\title{
O Brasil em tempos de independência - um estudo histórico de design e sociedade
}

\author{
Brazil in Times of Independence - a Historic Study of Design and Society \\ Mara Rúbia Sant'Anna-Muller
}

\section{Resumo}

Analisando o cenário nacional durante o reinado de D. Pedro I, percebeu-se a ênfase dada pela realeza na implantação de cerimoniais que atestassem sua posição e soberania. A absorção destes símbolos pela sociedade foi determinante para a construção das sociabilidades da época, caracterizadas pela tentativa de reprodução dos modelos europeus em terras tropicais.

Este estudo teve como objetivo analisar como alguns hábitos e costumes dos grupos sociais no âmbito da aparência, campo privilegiado do design, foram determinantes no sentido de afirmar ou não a independência da nação recém constituída.

Palavras-chaves: Aparência, sociabilidades, design

\section{Abstract}

Analysis of the national scenery during the kingdom of Dom Pedro I reveals the emphasis given by royalty to the implantation of ceremonies that attest to position and sovereignty. The absorption of these symbols by society was very important for the construction of sociabilities of the epoch, which were characterized by the attempt to reproduce European models in tropical lands.

The purpose of this study is to analyze how some habits and customs of the social groups in the realm of appearance, the privileged field of design, were determining factors in the affirmation of independence of the recently constituted nation.

Keywords: appearance, sociabilities, design 


\section{Introdução}

Após a declaração da independência, o Brasil tenta, através da figura do Imperador, estabelecer parâmetros para constituir-se como uma nação.

A partir da coroação de D. Pedro I, a realização de festividades que reuniam os grupos sociais e o olhar do estrangeiro sobre este povo, procuramos analisar a aparência que regia a sociabilidades da época, realizando assim um estudo histórico do âmbito da moda brasileira.

Desenvolvendo o projeto de pesquisa "Brasil por suas aparências - uma história da moda no Brasil", constatamos no olhar do estrangeiro, elementos curiosos à formação de uma elite nacional. Porém, "eram tantas e tão marcantes as diferenças entre este povo que não era possível identificar quem eram os outros para dizer quem éramos nós". Neste texto, devido à restrição de páginas exigida, abordamos apenas uma faceta destas interfaces entre design e sociedade logo após o Grito da Independência.

\section{Metodologia}

Este estudo foi construído a partir de referências bibliográficas consagradas sobre a história do Brasil Império e do tratamento de fontes escritas e visuais, como relatos de viajantes e obras artísticas de relevância na história da arte brasileira. A partir das fontes visuais, utilizando metodologia adequada para o estudo iconográfico e iconológico pautado por historiadores como Francis Haskell (1995), foi realizada uma análise cuidadosa da produção e disposição da temática da independência a partir de ícones e índices dos discursos construídos nas narrativas visuais. Da mesma forma se procedeu em relação às fontes escritas, sobre as quais se aplicou a análise do discurso como José Fiorin (1989) nos ensina.

\section{Não bastou gritar a independência:}

Superadas as dificuldades do governo de D. João VI no estabelecimento de uma Corte no país, é no reinado de D. Pedro I, especialmente a partir do Grito de Independência, que a necessidade da construção de uma identidade para esta Corte a partir de rituais, costumes e espaços de sociabilidades tornaram-se imprescindíveis.

Após a independência política de 1822 e a coroação de D. Pedro I em dezembro do mesmo ano, observou-se a necessidade de se investir em um cerimonial da realeza brasileira e no estabelecimento de determinadas memórias sociais. A própria cerimônia em si é um marco ao tentar reproduzir nos trópicos, simbologias originais da realeza européia.

Portanto, a nova nação nasceu no ato da coroação de um Imperador, com toda a pompa que a elite local desejava. Inaugurado o primeiro reinado, uma infinidade de festas e eventos comemorativos multiplicaram-se pela capital alimentando a necessidade da elite local de exibirse.

É nas festas, principalmente nos bailes, que toda a pompa se fazia presente. Em uma seqüência de rituais, os eventos incluíam músicas, contradanças e valsas, com pausas para apreciação de chás e doces, encerrando-se com uma ceia. (Apud SANT’ANNA, 2008).

Essa encenação acontecia também nas cerimônias públicas onde a monarquia recebia lugar de destaque. Entrava em cena um grande jogo simbólico, onde a realeza apresentava-se como personagem freqüente à frente dos Cortejos, vestindo trajes de gala e transformando esses eventos em verdadeiros espetáculos.

Para a elite e a Corte, mesmo os rituais católicos, como freqüentar a igreja aos domingos, eram uma ocasião perfeita para exibir nas ruas os mais requintados trajes. Às missas juntavam-se as procissões, estas, inclusive em grande número, concorriam entre si para mostrar qual apresentaria maior requinte. O catolicismo no Brasil era mais usado como palco para ostentar a construção de uma identidade social através da aparência do que para a prática da 
religião propriamente dita. Esta encenação proporcionava vantagens ao comércio local que fornecia os paramentos necessários às famílias ricas, como também a decoração dos locais onde acontecia o evento. Muitas destas festas religiosas duravam dias, seguidos de fogos e entretenimento que nada tinham de religiosos.

As ocasiões festivas e de encontro social davam aos Cortesãos cariocas o ensejo de se exibir e mostrar o quanto aptos estavam de serem semelhantes aos seus pares de outras Cortes.

Em contraposição a esse olhar da elite branca, que em tudo procurava parecer-se com os modelos europeus e para quem cor e classe social se fundiam, branqueando ricos e escurecendo pobres, para os estrangeiros, o povo brasileiro era um amontoado de negros, mestiços e gente sem valor. Estes vinham ao Brasil em busca de um exótico que seu romantismo evocava como necessidade de vida. (SANT'ANNA, 2008).

O próprio Jean Baptiste Debret sentia-se atraído pelos negros e índios que encontrava nas terras brasileiras, tanto quanto pelos hábitos dos brancos que aqui viviam e de tão "interessantes" ao pintor se tornavam motivo principal de suas aquarelas. Rugendas, ao seu lado, completava o quadro de uma elite que vivia enfeitada de paramentos estrangeiros e abusando de uma proximidade com a cultura européia que, para os pintores, realmente nada tinha de próxima. (Apud SANT'ANNA, 2008)

Debret registrou em seu livro as maneiras dos cariocas se vestirem e considerou que as mulheres vestiam-se com cores alegres e brilhantes, porém de uma maneira estranhamente requintada. Transformavam os modelos trazidos da França em algo mais pomposo e, segundo os gostos das clientes brasileiras, mais adequado ao prestígio de quem pertencia à Corte.

As mulheres de São Paulo, na visão de Schlichthorst (Apud SANT'ANNA, 2008) eram mais belas, com olhos pretos e vivos, sobrancelhas bem desenhadas, cabelos negros e abundantes somados a um porte altivo. Em suas vestimentas davam ênfase as cores, pois o branco era associado às roupas dos escravos. Meias de seda e sapatos luxuosos eram acessórios imprescindíveis e foram adotados também pelas estrangeiras que vieram posteriormente, assim como o emprego de escravos para a realização de toda forma de trabalho.

As províncias brasileiras que existiam ao norte e ao sul da Corte viviam das atividades econômicas pouco rentáveis e sua elite era um espelho desse desolamento econômico. Nessa condição pouco favorável as elites regionais gozavam de poucos privilégios no começo do século XIX, tendo a independência representado muito pouco avanço para eles. Disso resulta que os viajantes anotaram muito mais pobreza e misérias ao longo das províncias que encontravam pelo Brasil a fora, do que do luxo.

No mundo provincial jogava-se a bicha, a douradinha, o bilhar como na Corte era costume também. Nas vestimentas, segundo as descrições de "Memória Estatística do Império do Brasil”" (Apud SANT'ANNA, 2008), usavam-se calções de cor, casacões, chapéu alto, espadim nos dias de gala e pelos mais ricos, cabeleira de rabicho; as senhoras usavam vestidos redondos, cheios de anáguas, curtos o suficiente para que as botinas de saltos vermelhos fossem bem apreciadas. As mantilhas, tradição vestimentar portuguesa preservada, foram usadas por longos anos a despeito das tendências de moda que a Corte ditava após copiá-las de Paris. Já em São José dos Campos as mulheres não usavam mantilhas ou véus e seus cabelos eram mesmo desarrumados e trajavam uma túnica de algodão grosso, quase sempre rasgada e suja.

Visitando a praia do Anjo, nas vizinhanças de Cabo Frio, Saint-Hilaire admirou-se de como a pobreza das casas, melhor das choupanas, contrastava com a elaboração dos trajes de suas proprietárias: "Elas usavam vestidos de musselina bordada. Xales de musselina ou de seda, colares e brincos, e segundo a moda geralmente seguida pelas brasileiras traziam seus longos cabelos presos no alto por uma travessa", (SAINT-HILAIRE, 1938).

No Rio Grande do Sul, Saint-Hilaire encontrou mulheres que julgou muito parecidas com as camponesas européias: "bonitas, brancas, coradas" e que ainda eram "acanhadas, pouco aparecendo e jamais comendo em nossa presença". Essas mulheres mais decentes, segundo o estrangeiro, usavam "vestidos de chita e um fichu; cabelos armados com uma travessa; pernas 
nuas", ou seja, eram simplesmente vestidas de um vestido pobre, agasalhadas com um xale pequeno e triangular, com os cabelos ligeiramente arrumados e sem meias.

Como vemos, as mulheres que povoavam o Brasil além da Corte foram julgadas pelos viajantes, nossos depoentes deste passado distante, como belas na medida em que se aproximavam das européias e como amigáveis na medida em que sabiam conservar a moral sexual sem tornar-se arredia ao contato com os homens.

\section{Considerações finais}

Os sujeitos históricos são pessoas guiadas por suas vaidades e orgulhos, os quais, numa sociedade já possuidora do ethos moda, se realiza por consumos e exibições considerados meios de valorização dos sujeitos.As sociedades provinciais, com suas especificidades, a despeito da independência formal, mantinham-se atreladas aos costumes portugueses. No âmbito da aparência, seguiam-se os princípios de uma reprodução dos modelos europeus, com pequenas adaptações que o contexto dos trópicos sugeria. Mesmo que houvesse um Imperador a frente do teatro da Corte, as discrepâncias sociais, tão intensas como as dificuldades econômicas reinantes, impediam a independência dos modelos europeus para os grupos sociais na exibição de seus papéis.

Assim podemos concluir que os hábitos e costumes dos grupos sociais, no âmbito da aparência, campo privilegiado do design, durante o império de D. Pedro I, foram elementos determinantes na manutenção da dependência da nação recém constituída.

\section{Referências:}


FIORIN, José Luiz. Elementos de análise do discurso. São Paulo: Contexto: EDUSP, 1989.

HASKELL, Francis. L'historien et les images. Paris: Gallimard, 1995.

RENAULT, Delso. O Rio antigo nos anúncios de jornais. Rio de Janeiro: José Olympio, 1969.

RODRIGUES, José Honório. Independência: revolução e contra- revolução. Vol.2. Rio de Janeiro: Fco. Alves, 1975, p. 140.

SANT'ANNA, Mara Rúbia. Império - uma civilização nos trópicos. In: Brasil por suas aparências - volume 2. Florianópolis: UDESC, 2008. [Cd-rom].

SANT'ANNA, Mara Rúbia. Teoria de Moda, sociedade, imagem e consumo. São Paulo: Estação das Letras, 2007. Cap.1

SAINT HILAIRE, Segunda viagem do Rio de Janeiro a Minas Gerais e a São Paulo. São Paulo : s.e., 1938, p. 151.

${ }^{\mathrm{i}}$ SAINT-HILAIRE, 1938 